NASA Technical Memorandum 106032

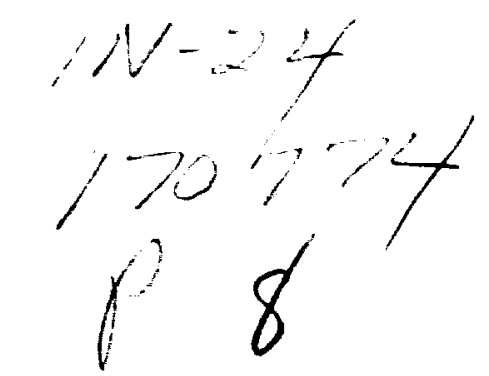

\title{
Soft Computing in Design and Manufacturing of Advanced Materials
}

Krzysztof J. Cios

University of Toledo

Toledo, Ohio

and

George Y. Baaklini and Alex Vary

Lewis Research Center

Cleveland, Ohio

Prepared for the 1993 American Society of Mechanical Engineers cosponsored by the IGTI and ASME

Cincinnati, Ohio, May 24-27, 1993 
$-2$

, 


\title{
SOFT COMPUTING IN DESIGN AND MANUFACTURING OF ADVANCED MATERIALS
}

\author{
Krzysztof J. Cios \\ University of Toledo \\ Toledo, OH 43606
}

\author{
George Y. Baakdini and Alex Vary \\ NASA Lewis Research Center \\ Cleveland, OH 44135
}

\begin{abstract}
The goal of this paper is to show the potential of fuzzy sets and neural networks, often referred to as soft computing, for aiding in all aspects of manufacturing of advanced materials like ceramics.
\end{abstract}

In design and manufacturing of advanced materials it is desirable to find which of the many processing variables contribute most to the desired properties of the material. There is also interest in real time quality control of parameters that govern material properties during processing stages. This paper briefly introduces the concepts of fuzzy sets and neural networks and shows how they can be used in the design and manufacturing processes. These two computational methods are alternatives to other methods such as the Taguchi method. The two methods are demonstrated by using data collected at NASA Lewis Researcb Center. Future research directions are also discussed.

\section{INTRODUCTION}

In this paper our intent is to show the potential of soft computing methods, namely fuzzy sets and neural networks, in design and fabrication of ceramics. Soft computing in our framework is utilized to identify trends indicating which input variable contributes most to the increase of a desired output parameter, say strength. Such identification can potentially speed up the process of designing a new material. Human designers can easily notice such trends for a few variables but it becomes very difficult to do so for a large number of variables.

Initially, we shall briefly introduce fuzzy sets and neural networks. Then, we shall illustrate the power of soft computing for fabrication of new materials by showing some of the results obtained in our previous work $[1,2]$ in which we utilized the data originally collected by Sanders and Baaklini [3]. Results on the data from 273
NASA $6 \mathrm{Y}$ silicon nitride $[1,2,3]$ modulus of rupture bars tested at room temperature will be given.

Three input variables, namely milling time of the composition powder, the sintering time of the modulus of rupture test bars, and the nitrogen pressure employed during sintering, are considered. The relationship between the above listed input variables and the flexural strength and density as output variables, found by soft computing methods, will be shown and commented on.

\section{BACKGROUND}

The reason of choosing silicon nitride is that it is an important material for heat engine applications due to its high operating temperature, reduced weight, resistance to oxidation, thermal shock resistance and good high-temperature strength [4]. Estimates of potential efficiency improvements for automotive engines with structural ceramic components range from 30 to 50 percent over current engine technology. Ceramics consist of non-strategic materials that are relatively inexpensive. Their scatter in strength and low toughness are generally attributed to discrete defects such as voids, inclusions, and cracks introduced during processing [3]. Current cost-effective fabrication procedures also frequently produce ceramics containing bulkdensity variations andmicro-structural anomalies that can adversely affect performance [4].

Scatter in mechanical properties of ceramics is a great drawback from a designtreliability stand point. This scatter is attributed to defects and inhomogeneities occurring during processing of silicon nitride powder compositions and during part fabrication. From the research work on silicon nitride composition at the National Aeronautics and Space Administration Lewis Research Center it was evident that density gradients were strongly dependent upon sintering conditions [5]. The results of an investigation of one silicon nitride composition involving sintering trials of 21 batches of 
material are described in [3], and this particular data is utilized bere to show that soft computing is a useful tool which can be either used on its own or in a bybrid system to provide much needed information to advanced materials designers.

\section{SOFT COMPUTING METHODS Basics of Fuzay Sets}

Fuzzy sets were developed by Zadeb as means for dealing with vague information, in everyday language represented by linguistic variables like bigh, low, more or less, etc. [6]. Fuzzy set theory provides a natural approach to problems in which ohjects change their membership in classes gradually. Fuzzy sets allow us to deal with pbenomena that are vague, imprecise, too complex or too ill defined to be analyzed by conventional mathematical tools [7]. Definitions essential for subsequent explanation of the used methods follow.

Let $R$ be the set of real numbers and $U$ be the conventional (crisp) set. Let $u$ be a generic element of $U$. A fuzzy subset $A$ of $U$ is defined by a membership function $\mu_{A}: U \rightarrow[0,1]$. The fuzzy subset $A$ of $U$ can be expressed as:

$$
\left.A=\left\{\mu_{A}(u)\right] u ; u \varepsilon U, \mu_{A}(u) \varepsilon[0,1]\right\}
$$

where $\mu_{A}$ is referred to as the grade of membership of $u$ in $A$.

The support of $A$, is the set of elements in $U$ whose memberships in fuzzy subset $A, \mu_{A}(u)$, are positive:

$$
\operatorname{Supp}(A)=\left\{u l u \in U, \mu_{A}(u)>0\right\}
$$

As an example, let us define a fuzzy subset "old" on a crisp set of people of different ages. The support of "old" may be defined on nine points for ages 10 through 100 (in steps of ten). Grades of membership for these points can be assigned as $.01 / 10, .05 / 20, .1 / 30$, $5 / 40, .7 / 50, .8 / 60, .9 / 70,1 / 80,1 / 90,1 / 100$; where $\mu_{\text {old }} /$ means that $\mu_{\text {old }}$ is a grade of membership of element $u$ in a fuzzy subset "old". Thus, say, .7/50 means that a person who is 50 years old belongs to a fuzzy subset "old" with the grade of membership equal to 0.7 .

Aggregation of fuzzy sets is an operation by which several fuzzy sets are combined into a single set. In general, any aggregation operation is defined by the function

$$
\text { h: }[0,1]^{\mathrm{n}} \rightarrow[0,1]
$$

for some $n>=2$. When applied to $n$ fuzzy sets defined on $U, b$ produces an aggregate fuzzy set A by operating on the grades of membership of each element of $U$ in the sets being aggregated.

From the several classes of averaging operations we chose generalized means which is defined as follows:

$$
b_{\alpha}\left(a_{1}, a_{2}, \ldots a_{n}\right)=\left(\frac{a_{1}^{\alpha}+a_{2}^{\alpha}+\ldots+a_{n}^{\alpha}}{n}\right)^{\frac{1}{\alpha}}
$$

where $\alpha \in R(\alpha \neq 0)$ is a parameter by which different means are distinguisbed; $\alpha=2$ was used.

\section{Badial Basis Functions}

The other type of soft computing comprises neural networks. A neural network can be made to approximate any given function provided that the network bas a sufficient number of processing units, called neurons. In this paper we sball briefly describe a neural network algorithm called radial basis function (RBF) network [9]. It is a three layer network with "locally-tuned" processing units in the hidden layer. RBF neurons are centered at the training data points, or some subset of it, and each neuron only responds to an input which is closest to its center. The output layer neurons are linear or sigmoidal functions and their weights may be obtained by using a supervised learning method, such as a gradient descent method.

Figure 1 sbows a general RBF network with $n$ inputs and one linear output. This network performs a mapping $f: R^{n} \rightarrow R$ given by the following equation [10]:

$$
f(x)=\lambda_{0}+\operatorname{sUM}_{i=1}^{n_{T}} \lambda_{i} \phi\left(\left|x-c_{i}\right|\right)
$$

where $x \varepsilon R^{n}$ is the input vector, $\phi($.$) is a function from R^{n} \rightarrow R, \mid$ | denotes the Euclidean norm, $\lambda_{i}\left(0<=i<=n_{r}\right)$ are the weights of the output node, $c_{i}\left(0<=i<=n_{r}\right)$ are the $R B F$ centers, and $n_{r}$ is the number of the so-called RBF centers.

One of the most common functions used for $\phi($.$) is the Gaussian$ function:

$$
\phi\left(\left|x-c_{j}\right|\right)=\exp \left(-\frac{\left|x-c_{i}\right|^{2}}{\sigma_{1}^{2}}\right)
$$

where $\sigma_{1}$ is a constant which determines the width of the $\mathrm{i}$-th node.

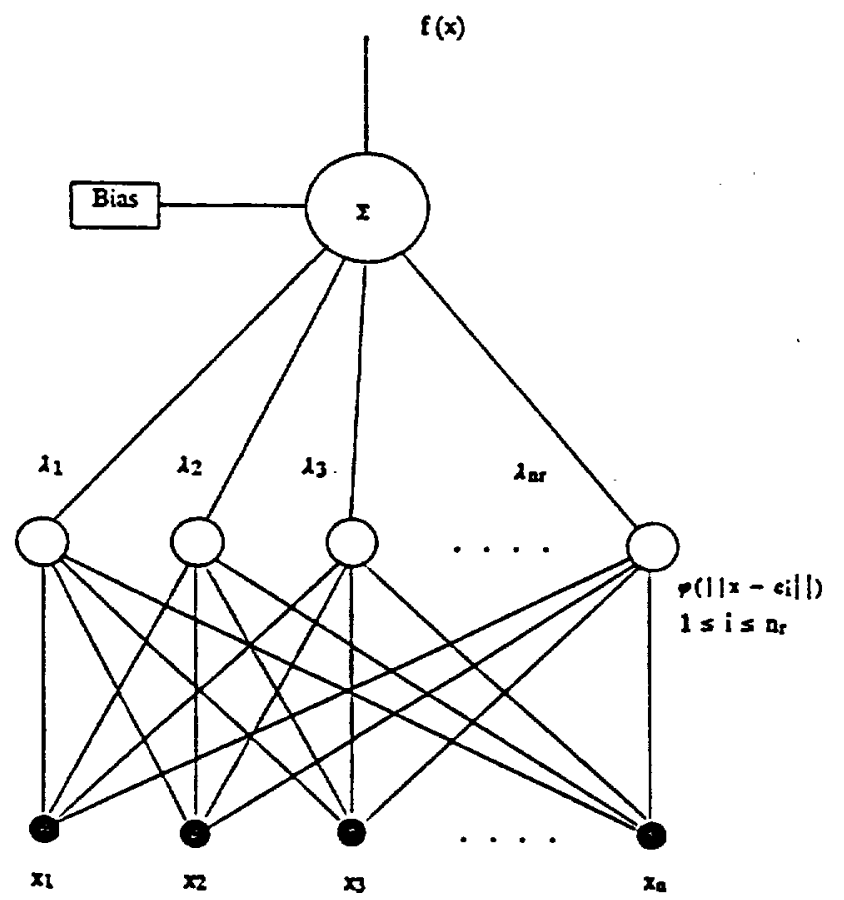

FIGURE 1. RADIAL BASIS FUNCTION NETWORK WITH SINGLE OUTPUT. 

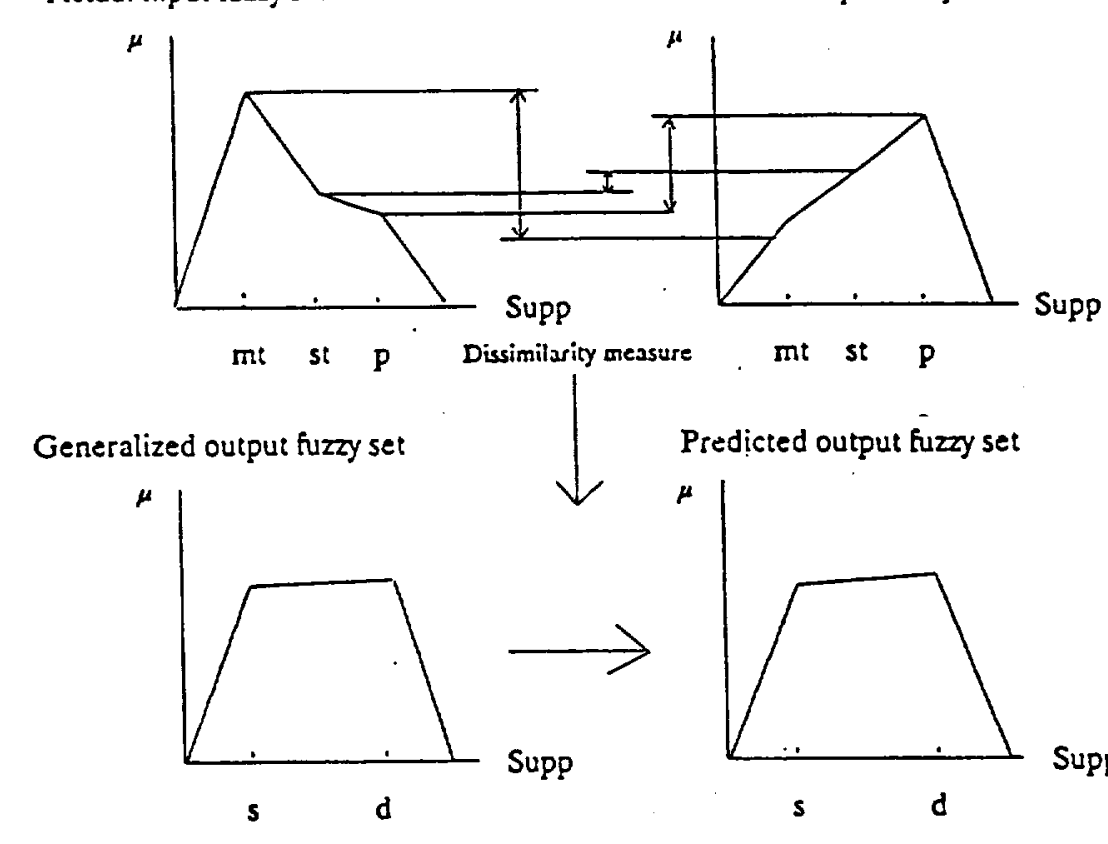

Predicted output huzzy set

FIGURE 2. EXPLANATION OF THE FUZZY PREDICTION METHOD.

This function has a maximum value of 1 when $\left|x-c_{j}\right|$ is 0 , and drops off to 0 as $\left|x-c_{i}\right|$ approaches infinity.

The centers of the RBF functions, $c_{i}$, are usually cbosen from the training data points $x_{i}(1<=i<=N)$. This method is known as the "neurons at data points" method [11]. For larger data sets, it is not practical to bave an RBF center at each data point, so other methods were developed to reduce the number of RBF centers. Some of them are the random selection of centers, clustering of data points, and orthogonal least squares reduction [10].

The random selection method simply uses a random selection of $n_{1}$ centers from $\mathrm{N}$ data points, where $n_{T}<N$. If the desired outputs are discrete and represent, say, $\mathrm{C}$ different classes, then clustering methods sucb as $\mathbf{k}$-means clustering [11] may be used to cluster the data points within each class. A very effective method of choosing a set of RBF centers from the training data is the orthogonal least squares reduction method [10] which enables the selection of the most significant RBF centers from a given training data set.

\section{METHOD OF MAKING PREDICTIONS AND DATA USED}

For the room temperature, 18 different combinations of milling time, sintering time, and nitrogen pressure yielded the composition strengths and densities sbown in Table $I$.

In order to validate the soft computing methods predictions, we needed to test the system using known test vectors to evaluate the error of predictions. We were particularly interested in the ability of the network to predict the output values for batch number $6 Y 25$, as

\section{TABLE I: STRENGTH AND DENSITY AT ROOM TEM- PERATURE FOR DIFFERENT PROCESSING AND SINTERING CONDITIONS.}

\begin{tabular}{|c|c|c|c|c|c|c|}
\hline $\begin{array}{c}\text { Batch } \\
\#\end{array}$ & $\begin{array}{l}\text { No. of } \\
\text { speci- } \\
\text { men }\end{array}$ & $\begin{array}{c}\text { Mitling } \\
\text { time } \\
\text { [or] }\end{array}$ & $\begin{array}{c}\text { Sintering } \\
\text { time } \\
\text { [tr] }\end{array}$ & $\begin{array}{c}\text { Nitrogen } \\
\text { pressure } \\
\text { [MIPa] }\end{array}$ & $\begin{array}{c}\text { Acujal } \\
\text { Strength } \\
\text { [MPa] }\end{array}$ & $\begin{array}{l}\text { Actual } \\
\text { density } \\
{\left[g / \mathrm{cm}^{3}\right]}\end{array}$ \\
\hline $\begin{array}{l}\sigma Y 1 B \\
6 Y 2 B \\
6 Y 11 \\
\sigma Y 12 \\
\sigma Y 13 \\
\sigma Y 14 \\
\sigma Y 1516 \\
\sigma Y 17 \\
6 Y 18 \\
6 Y 19 \\
6 Y 20 \\
6 Y 23 \\
\sigma Y 24 A \\
6 Y 24 B \\
6 Y 25 \\
6 Y 26 A \\
6 Y 26 B \\
\text { GY28 }\end{array}$ & $\begin{array}{l}30 \\
30 \\
15 \\
15 \\
15 \\
14 \\
19 \\
10 \\
10 \\
10 \\
10 \\
15 \\
15 \\
15 \\
10 \\
15 \\
15 \\
10\end{array}$ & $\begin{array}{r}24 \\
24 \\
100 \\
300 \\
100 \\
300 \\
24 \\
100 \\
100 \\
100 \\
100 \\
100 \\
100 \\
100 \\
300 \\
100 \\
100 \\
100\end{array}$ & $\begin{array}{l}1 \\
1 \\
1 \\
1 \\
1 \\
1 \\
2 \\
2 \\
1.5 \\
1.5 \\
2 \\
1.25 \\
1: 25 \\
2 \\
2 \\
1 \\
1 \\
2\end{array}$ & $\begin{array}{l}25 \\
25 \\
25 \\
25 \\
25 \\
25 \\
5 \\
5 \\
5 \\
5 \\
5 \\
5 \\
3.5 \\
35 \\
5 \\
35 \\
5 \\
5\end{array}$ & $\begin{array}{l}556 \\
532 \\
490 \\
579 \\
684 \\
746 \\
664 \\
646 \\
608 \\
570 \\
650 \\
631 \\
586 \\
619 \\
714 \\
479 \\
503 \\
671\end{array}$ & $\begin{array}{l}3.12 \\
3.18 \\
3.23 \\
3.25 \\
3.24 \\
3.24 \\
3.22 \\
3.23 \\
3.21 \\
3.22 \\
3.22 \\
3.24 \\
3.26 \\
3.26 \\
3.28 \\
3.20 \\
3.18 \\
3.21\end{array}$ \\
\hline
\end{tabular}

this batch number represented the optimum combination for the input variables [3]. Thus, batch number 6Y25 was first removed from the data. The data were then pseudo-randomly divided into two parts: $70 \%$ for training and the remaining $30 \%$ for testing. Batch number $6 Y 25$ was then inserted into the test data set. 
Next, we wanted to see whether it was possible to find combinations of input variables, other than those used in [3], which would result in the strength and density values close to the optimal (6Y25) value. Thus, a training data set consisting of all the batch numbers (100\%) except 6Y25 was created. Batch number 6Y25 was then placed in the training data set and we made predictions for different, not tried by experiments in [3], combinations of the input vectors.

For the fuzzy sets, the collected data was used to define fuzay sets for each batch for both input and output variables. The input fuzzy sets were defined for three values of support (nitrogen pressure, sintering time, and milling time) while the output fuzzy sets had support of two elements (flexural strength and density). The grades of memberships were normalized elementwise, and the normalization was repeated for every step of prediction. The resulting membership grades were combined by means of generalized mean operation. After that a dissimilarity measure (a modified Hamming distance [2]) was used to calculate the difference between the actual and generalized fuzzy sets of input parameters. Next, the k-fraction of the measure, where $\varepsilon \varepsilon(0,1)$ was either added to or subtracted from the geveralized grades of memberships of the output parameters. The graphical explanation of the method is shown in Figure 2. It shows the 6 Y12 test batch. The generalized input fuzzy set consists of grades of membership obtained by generalized mean operation performed on normalized values of input parameters: milling time (mt), sintering time (st), and pressure (p). The actual input fuzzy set represents normalized values of $6 \mathrm{Y} 12$ batch input. The dissimilarity measure was then used to calculate the sum of the elementwise differences between grades of membership of actual and generalized input fuzzy sets. The k-fraction of the measure was then added to the grades of membership of the generalized output fuzzy set. The generalized output fuzzy set was obtained by generalized mean operation performed on normalized values of output parameters, strength (s) and density (d). Addition of k-fraction of dissimilarity measure results in the predicted fuzzy set. The latter is then compared with the actual grades of membership obtained by normalization of the values of the $6 \mathrm{Y} 12$ batch output thus yielding a measure of error for strength and density.

\section{RESULTS}

\section{Utilization of Furzy Sete}

The method described above for fuzzy sets was used to predict, for randomly chosen values of input variables, the values for output variables, namely, flexural strength and density of batch samples at room temperature. This was done in order to estimate the error. The overall results are shown in Table II. Since the errors were reasonably small, we made predictions for selected new, not tried in [3], combinations of processing and sintering variables. Table III shows the results. We can notice that the resultant strengths and densities are lower than the one for the optimum batch (6Y25 was the optimum because of low scatter, not shown in Table 1 . This result was expected since fuzzy systems are bounded, which was shown in [12].

TABLE II: OVERALL RESULTTS FOR STRENGTH AND DENSITY FOR ROOM TEMPERATURE.

Strength - average \% error for all test vectors and (6Y25) 5.7 (4.4)
Density - average $\%$ enor for all test vectors and (6Y25) $24(0)$
TABLE III: PREDICTION OF INPUT VARIABLES FOR HIGHEST STRENGTH AND DENSITY, FOR ENTIRE TRAINING DATA FROM TABLE I.

\begin{tabular}{|c|c|c|c|c|}
\hline $\begin{array}{c}\text { Milling } \\
\text { time } \\
{[\mathrm{mr}]}\end{array}$ & $\begin{array}{c}\text { Sintering } \\
\text { time } \\
{[\mathrm{hr}]}\end{array}$ & $\begin{array}{c}\text { Nitrogen } \\
\text { Pressure } \\
{[\mathrm{MPa}]}\end{array}$ & $\begin{array}{c}\text { Predicted } \\
\text { Strength } \\
\text { [Mpa] }\end{array}$ & $\begin{array}{c}\text { Predicted } \\
\text { Density } \\
\text { [g/cm] }\end{array}$ \\
\hline 150 & 1.5 & 3 & 596 & 3.15 \\
175 & 1.5 & 3 & 604 & 3.18 \\
200 & 1.5 & 3 & 611 & 3.21 \\
200 & 1.75 & 4 & 634 & 3.28 \\
250 & 1.5 & 3 & 619 & 3.25 \\
250 & 1.5 & 4 & 634 & 3.28 \\
250 & 1.75 & 4 & 649 & 3.28 \\
300 & 1.5 & 4 & 649 & 3.28 \\
300 & 1.75 & 4 & 656 & 3.28 \\
300 & 2 & 5 & 686 & 3.28 \\
\hline
\end{tabular}

\section{Utilization of Neural Networke}

The RBF networiss were trained using the same training data as described above. The "neurons at data points" method was used to set up the hidden layer. The gradient descent method was used to train the output layer peurons which use sigmoidal function. The RBF networks consisted of three input neurons and two output neurons which corresponds to the number of input and output variables, respectively. The number of neurons in the hidden layer depended on the number of the training vectors. The overall results are shown in Table IV. Table $V$ shows predictions made for selected, not previously tried [3], combinations of processing and sintering variables that resulted in strengths and densities similar to that of the optimum batch (6Y25).

\section{TABLE IV: OVERALL RESULTS FOR STRENGTH AND DENSITY FOR ROOM TEMPERATURE.}

Strength - average \% error for Density - average \% error for all test vectars and (6Y25) all test vectors and (6Y25) $1054(10.17)$ $0.98(250)$

TABLE V: PREDICTION OF INPUT VARIABLES FOR HIGHEST STRENGTH AND DENSITY, FOR ENTIRE TRAINING DATA FROM TABLE I.

\begin{tabular}{|c|c|c|c|c||}
\hline $\begin{array}{c}\text { Milling } \\
\text { time } \\
{[\mathrm{br}]}\end{array}$ & $\begin{array}{c}\text { Sintering } \\
\text { time } \\
{[\mathrm{hr}]}\end{array}$ & $\begin{array}{c}\text { Nitrogen } \\
\text { Pressure } \\
\text { [MPa] }\end{array}$ & $\begin{array}{c}\text { Precicted } \\
\text { Strength } \\
\text { [MP2] }\end{array}$ & $\begin{array}{c}\text { Predicted } \\
\text { Density } \\
\text { [g/cm] }\end{array}$ \\
\hline 150 & 1.5 & 3 & 692 & 3.28 \\
175 & 1.5 & 3 & 700 & 3.28 \\
200 & 1.5 & 3 & 706 & 3.28 \\
200 & 1.75 & 4 & 689 & 3.27 \\
250 & 15 & 3 & 709 & 3.28 \\
250 & 1.5 & 4 & 705 & 3.28 \\
250 & 1.75 & 4 & 705 & 3.28 \\
300 & 15 & 4 & 711 & 3.28 \\
300 & 1.75 & 4 & 713 & 3.28 \\
300 & 2 & 5 & 712 & 3.28 \\
\hline
\end{tabular}




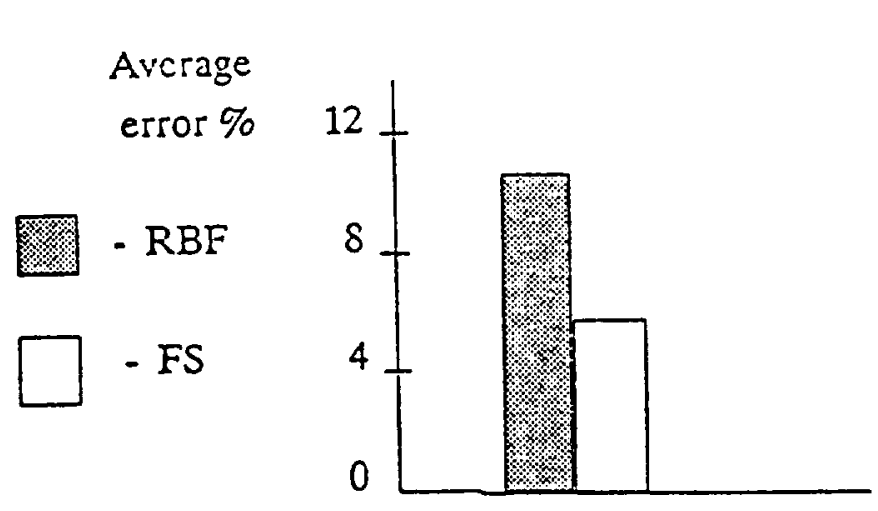

Error in strength

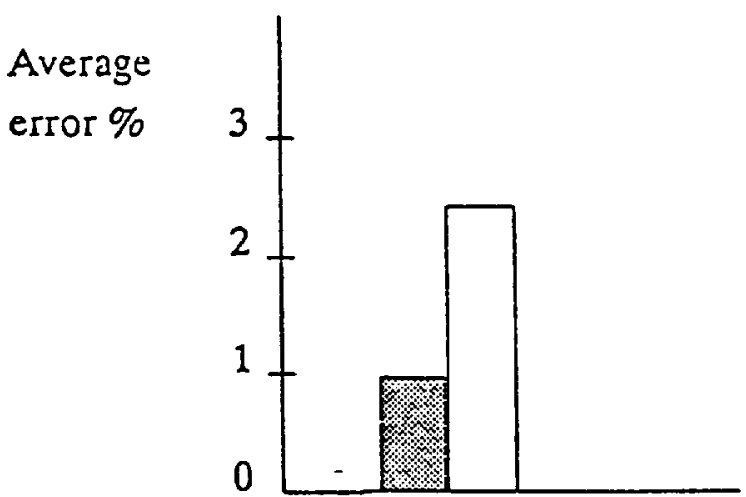

Error in density

FIGURE 3. AVERAGE ERRORS IN PREDICTING STRENGTH AND DENSITY.

The information in Table $V$ suggests that there may bave been other, than those tried in [3], combinations of sintering and processing variables that would have produced results almost as good as that obtained for 6Y25 [3] but more efficiently. For example, in Table $V$, using a milling time of 250 bours, a sintering time of 1.5 bours, and a nitrogen pressure of $3 \mathrm{MPa}$, the network predicts that a strength of $709 \mathrm{MPa}$ can be obtained. This is only slightly less than the optimal value for 6 Y25 but with a reduction in milling time of 50 hours. A word of caution here. Although the confidence in prediction results for strength and density lies within $11 \%$ and $2.5 \%$ (from Tables $I$ and $\mathrm{V}$ ), respectively, these predictions need to be confimed by fabrication of ceramics using the suggested in Table $\mathrm{V}$ input parameters. From the theoretical point of view, if the relation between the input and output variables is a smooth function, either increasing or decreasing, then RBF predictions will be accurate and valid for sufficiently large training data set.

\section{DISCUSSION}

If in the process of designing new ceramics the designers were to use soft computing in order to notice the correlations between the input and output variables, it might greatly sborten the fabrication cycle. We bave shown that this was true for even the small number of input variables. If larger number of input variables could be used that would certainly improve the reliability of predictions and their accuracy. Soft computing can be also seen as an alternative to the Taguchi method [13].

Predicting bulk density of ceramics was more successful than predicting strength. This may be explained by noticing that bulk density is more directly related to milling time, sintering time, and pressure, whereas the flexural strength is additionally dependent on pore morphology, on microstructure, and on the presence of failure causing defects.

Comparison of results obtained by using fuzzy sets [2] with those obtained by using netral networks [1] indicates that both were successful in modelling relationsbips existing between the processing variables and output variables. This is shown graphically, based on Tables II and IV, in Figure 3. As can be seen, small differences exist in terms of errors. Fuzzy sets were slightly better than neural networks in predicting strength, which is statistically varied as a result of the fabrication process. On the otber band, the more precise relationship between the input variables and density was modelled better using neural networks.

When we tried to predict the untried combinations of input variables which might yield the highest ("optimum") values for streng th and density, Tables III and $\mathrm{V}$, the results were again slightly different. Now, bowever, in order to make a statement which method gives more accurate predictions, the real experiments will need to be performed and errors calculated. In an absence of such an experiment we cannot compare the two methods of predictions. We can only say, from Tables $I$ and $\mathrm{IV}$, that our confidence in predicting strength is larger for fuzzy sets, while for predicting density it is larger for neural networks.

\section{CONCLUSIONS}

We have shown that soft computing, if it were the part of the design process, could belp in optimizing the process of fabricating ceramics with high strengtb, accompanied by low scatter. We approached the problem by concentrating on three input variables and two output parameters. The available data set was divided into training and test parts. The former was used for training neural networks and defining fuzzy sets, and the second to validate them on the test part as to how accurately they can predict the strength and density of the test set given new "unknown" inputs.

Then, we have sbown that it was possible to indicate other, than those tried, combinations of input variables which resulted in at least as strong material as the one from the known training data (6Y25), but more "optimal" in terms of either sborter milling and sintering times, or lower pressure.

Soft computing methods may not necessarily yield the optimal solution, but most of the time they will give an acceptable, low cost solution. In many situations, a robustly obtained "good" solution is preferred to an optimal solution which may take a lot of time to compute.

The obtained results indicate that soft computing can be a powerful tool for both process modeling and process control. It can speed the development and fabrication of emerging ceramic materials. Thus, soft computing might help to capture imprecise relationships between the input variables and output parameters. In turn, these 
leamed relationships can be used for predicting strength and density for new combinations of the input variables. The reliability of our predictions was validated by calculating the errors on the test data encompassing $30 \%$ of available data. The maximum combined error, for both methods, for the strength was less than or equal to $10.54 \%$, and for density it was less than or equal to $2.4 \%$. However, between the two methods, the combined minimum error was less than or equal to $5.7 \%$ for strength, and $0.98 \%$ for density. The latter clearly shows that by using a hybrid approach one can achieve better results.

\section{FUTURE RESEARCH DIRECTIONS}

In the future we envision a more versatile and powerful bybrid system which will combine the two soft computing methods with genetic algorithms and numerical optimization methods. Genetic algorithms will enable exploration of the entire design space in search for global optimum. Such a system would rapidly optimize the process of ceramics fabrication as a function of input variables and process parameters. The hybrid system sbould also incorporate the existing knowledge of the ceramics fabrication experts. After such system has been developed the next step would be to move to the problem of optimal design of other composite materials such as ceramic- and metal-matrix composites.

Soft computing, bowever, is not a panacea for solving problems. It should not be used in situations where mathematically sound models are known. However, since the two soft computing methods are inherently parallel, and thus easily implementable in hardware, they might prove advantageous for real-time applications.

\section{AEFERENCES}

[1] Cios KJ., Baaklini G.Y., Vary A. and Tjia R.E., "Radial Basis Function Network Learns Ceramic Processing and Predicts Related Strength and Density," 1992, submitted.

[2] Cios K.J., Sztandera L., Baaklini G.Y. and Vary A., Fuzzy Sets Predict Flexural Strength and Density of Silicon Nitride Ceramics," Materials Evaluation, 1992, submitted.

[3] Sanders W.A. and Baaklini G.Y., "Correlation of Processing and Sintering Variables with the Strength and Radiography of Silicon Nitride," Ceramic Engineering and Science proceedings, vol. 7, no. 7-8, 1986, pp. 839-860.

[4] Klima S.J. and Baaklini G.Y., "Nondestructive Characterization of Structural Ceramics," SAMPE Quarterly, vol. 17, no. 3, 1986, pp. 13-19.

[5] Baaklini G., "NDE Reliability and Process Control for Structural Ceramics," Journal of Engineering for Gas Turbines and Power, vol. 109, 1987, pp. 263-266.

[6] Zadeh L., "Fuzzy Sets," Information Control, vol. 8, 1965, pp. 338-353.

[7] Cios K.J., Shin I. and Goodenday L., "Using Fuzzy Sets to Diagnose Artery Coronary Stenosis, IEEE Computer Magazine, vol. 24, no. 3, 1991, pp. 57-63.

[8] Klir G.J. and Folger T.A., "Fuzzy Sets, Uncertainty and Information," Prentice Hall, Englewood Cliffs, 1988.

[9] Moody J. and Darken C., "Fast Learning Networks of Locally-tuned Processing Units," Neural Computing, vol. 1, no. 2, 1989, Pp. $281-294$.
[10] Chen S., Cowan C.F.N. and Grant P.M., "Orthogonal Least Squares Learning Algorithm for Radial Basis Function Networks," IEEE Trans. Neural Networks, vol. 2, no. 2, 1991, Pp. 302-309.

[11] Zahimiak D.R., Chapman R., Rogers S.K., Suter B.W., Kabrisky M. and Pyati V., "Pattern Recognition using Radial Basis Function Networks," Conf. Aerospace Application of Al, Dayton, 1990, in press.

[12] Cios K.J. and Sztandera L.M., "Boundness and Equivalence of Fuzzy Systems and Feed Forwand Artificial Neural Networks," 1992, submitted.

[13] McEntire B.J., Tagliavore A.P., Heichel D.N., Bright E., Yeckley R.L., Holowczak J.E. and Quackenbush C.L., "Silicon Nitride Component Development for Advanced Gas Turbine Engines," Proceedings of the 27th Automotive Technology Development Contractors' Coordination Meeting, Society of Automotive Engineers, Inc., Warrendale, PA, 1990, pp. 341-349. 
Public reporting burden for this collection of information is estimated to average 1 hour per response, including the time for reviewing instructions, searching existing data sources. gathering and maintainin the collectioded, and completing and reviewing the collection of information. Send comments regarding this burden estimate or any other aspect of this gathering and maintaining the data needed, and completing and revem, to Washington Hesdquarters Senvices, Directorate for Information Operations and Reports, 1215 Jefferson collection of intormation, including sugpostions
1. AGENCY USE ONLY (Leave blank)
2. REPOAT DATE
April 1993
3. REPOAT TYPE AND DATES COVERED
Technical Memorandum

4. TITLE AND SUBTIRE

Soft Computing in Design and Manufacturing of Advanced Materials

6. AUTHOR(S)

- WU-510-01-50

Krzysztof J. Cios, George Y. Baaklini, and Alex Vary

7. PERforing ORganization MAME(S) AMd ADDRESS(ES)

National Aeronautics and Space Administration

Lewis Research Center

Cleveland, Ohio 44135-3191

Q. PERFORMING ORGANIZATION REPORT NUIMBER

E-7597

9. SPONSORINGMONITORING AGENCY RAME(S) AND ADDRESS(ES)

10. SPONSORINGMONTORING AGENCY REPORT NUMBER

National Aeronautics and Space Administration

Washington, D.C. 20546-0001

NASA TM-106032

11. SUPPLEMENTARY MOTES

Prepared for the 1993 American Society of Mechanical Engineers cosponsored by the IGTI and ASME, Cincinnati, Ohio, May 24-27, 1993. Krzysztof J. Cios, University of Toledo, Toledo, Ohio 43606 and George Y. Baaklini and Alex Vary, NASA Lewis Research Center. Responsible person, George Y. Baaklini, (216) 433-6016.

12.. DISTRIBUTIONAVAILABILTY STATEMENT

12b. DISTRIBUTION CODE

Unclassified - Unlimited

Subject Categories 24 and 38

13. ABSTRACT (Maximum 200 words)

The goal of this paper is to show the potential of fuzzy sets and neural networks, often referred to as soft computing, for aiding in all aspects of manufacturing of advanced materials like ceramics. In design and manufacturing of advanced materials it is desirable to find which of the many processing variables contribute most to the desired properties of the material. There is also interest in real time quality control of parameters that govern material properties during processing stages. This paper briefly introduces the concepts of fuzzy sets and neural networks and shows how they can be used in the design and manufacturing processes. These two computational methods are alternatives to other methods such as the Taguchi method. The two methods are demonstrated by using data collected at NASA Lewis Research Center. Future research directions are also discussed.

\section{SUBJECT TERMS}

High temperature materials; Monolithic ceramics; Fuzzy logic; RBF; Radial basis function; Neural networks

\begin{tabular}{|c|c|}
\hline 17. SECURTY CLASSIFICATION & 18. SECURTY CLASSIFICATION \\
OF REPORT & OF THIS PAGE \\
Unclassified & Unclassified
\end{tabular}

19. SECUATY CLASSIFICATION OF ABSTRACT Unclassified
15. NUMBER OF PAGES

08

16. PaICE CODE

$\mathrm{A02}$ 
